\title{
Atomic Energy - Its Release, Utilization, and Control ${ }^{*}$
}

\author{
R. A. MILLIKAN $\dagger$
}

The Proceedings of THE I.R.E. is publishing, in accordance with the policy of the Institute, a series of papers dealing with instrumentation and controls in the field of the production and utilization of fissionable materials. The members of the Institute present at the IRE West Coast Convention at Los Angeles in 1948 were fortunate in hearing a paper dealing with the broad aspects of atomic energy, delivered by a world-renowned physicist. The speaker was a Nobel prize winner, a pioneer in the field of studies of atomic structure and of cosmic rays, and a leader in physical research.

The utilization to best advantage of fissionable materials available on earth is manifestly of major human importance. The following paper deals primarily with this subject, and is commended to the attention of the readers of the PROCEEDINGS OF THE I.R.E. -The Editor.

I AM NOT presumptuous enough to assume that I can add much to the knowledge of physics - classical or modernpossessed by a group of well-trained, active, and competent radio engineers. I have only one advantage over you. Many of the developments which you have learned from books I have had first-hand contact with, for they have all come within my active lifetime - in fact, since 1895-so that I may be able to fill in details and experiences which might throw some new light into the darker corners of your pictures of events, and therefore be at least of some interest to you.

We physicists are wont to take Roentgen's discovery of $\mathrm{X}$ rays as marking the beginning of what we call modern physics and closing the period of classical physics. The practical dollar-and-cents value of that discovery of Roentgen's is brought home to every family on earth when it is presented with the doctor's bills for the $\mathrm{X}$ rays he now insists upon seeing before telling any one of the family what is the matter with him.

But now, going beyond mere dollar-andcents values, why was this discovery so important scientifically? This following incident in my life furnishes the answer. I had attended the convocation at the University of Chicago in the summer of 1894 at which Professor Michelson had said in his commencement address that it was probable that all the great discoveries in physics had already been made, and that further progress might have to be found in measurements in the sixth place of decimals. Again, in my second year of attendance at Columbia I had lived in a fifth-floor flat on Sixty-fourth Street, a block west of Broadway, with four other Columbia graduate students, one a medic and the other three working in sociology and political science, and I was ragged continuously by all of them for sticking to a "finished," yes, a "dead subject" like physics, when the new "live" field of the social sciences was just being opened up. But here in Roentgen's discovery, only one year later, was a door opening into a new, theretoforeundreamed-of field of physics, a big, qualiattive field which had nothing to do with great refinement of measurements, and there I was in Berlin in the year 1895-1896, participat-

* Decimal classification: 539. Original manuscript received by the Institute, January $12,1949$. Presented 1948 IRE West Coast Convention, Los Angeles,
Calif., September 30, 1948.

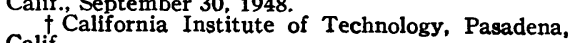

ing in the discussions just where and when it was being born. It was clearly just to be there in 1895 that $I$ had been born in 1868 !

The reason we physicists usually date the rise of modern physics from the discovery of $\mathrm{X}$ rays in December, 1895 - I shall here designate it as discovery number 1 -is that in the immediate train of that discovery, and stimulated by it, there followed quickly the discovery in Paris in 1896 essentially of the transmutation of the elements through Becquerel's proof of the existence of radioactivity-discovery number 2. Again, there followed a year later, with some aid from $\mathrm{X}$ rays, J. J. Thomson's demonstration in England, to practically everyone's satisfaction, of the concept of the negative electrons, called by Thomson "corpuscles," as fundamental constituents of all atoms in the universe- discovery number 3 . Further, these two discoveries were soon followed by Planck's even more fundamental one-discovery number 4 - conceived in the course of lectures I took with him in 1896; namely, the discovery of discontinuous, jump-like, or "quantum" energy and momentum changes. The reason this discovery had not been made earlier was that man here was entering a thus-far almost completely unexplored domain; namely, the domain of subatomic or microscopic, as distinguished from ordinary or macroscopic, energy and momentum exchanges. This field is most simply entered through photoelectric research, already found industrially useful. These three last discoveries-radioactivity, electronics, and quanta-actually determined the direction of my own study and research for the next fifty years.

Of these three great discoveries which were made in "the dead field of physics" during the last five years of the nineteenth century-namely, that of radioactivity, that of the negative electron as a fundamental constituent and cementing agent of all atoms in the universe, and that of the quantum as a fundamental unit involved in all atomicenergy transformations-the second, the electron, with its myriad of extensions and applications to radar, to communications of all kinds, to pictures, and to a score of other industries, has been the most useful to mankind; the first, radioactivity, and the third, quanta, the most revolutionary to human thought. Among the three, radioactivity claimed my own attention at Chicago first.

I have just said that radioactivity was revolutionary to human thought. That was because some, even of the "eternal atoms," namely, those of uranium and thorium, are unstable and are spontaneously throwing off with great energy pieces of themselves, thus transforming themselves into other atoms, following the universal tendency of matter to pass over into a state of maximum stability - a state that has already been practically reached by the atoms of all save a few very rare and very heavy elements; hydrogen, for the reasons soon to be given, being one exception.

But in 1905-a great year!-came the greatest advance of all-discovery number 5-when Einstein laid the foundations of a better understanding of the fundamental sources of energy in the universe than we had thus far had. He did it through the setting up, as a consequence of his special relativity theory, of the equation $E=m c^{2}$, in which $m$ is mass in grams, $c$ is the speed of light in centimeters $(30,000,000,000$ centimeters per second), and $E$ is energy in absolute energy units, namely, ergs.

The conception here is the exceedingly important one, namely, that matter is itself convertible into radiant energy, or, to take a concrete case, that the sun has been able to continue for the past three billion years pouring out heat and light at its present prodigious rate only because it is continuously feeding its own mass into its furnaces and consequently shrinking its waistband all the time, and sending the lost weight out in the form of radiant heat in accordance with the requirements of the foregoing equation. This equation has now been repeatedly checked in nuclear experiments in our own and in many other laboratories, and has never yet been found to fail, when the reaction could be made to take place.

But note that Einstein's equation does not indicate under what conditions, if any, the transformation of matter into radiant energy will actually take place, if at all. It only indicates the quantitative relations which must be fulfilled if and when the reaction does take place. The great practical significance of this equation will only be seen by looking more closely at the factors involved. It is to be noted that it says that if one gram of matter is transformed completely into ergs of energy, to get it into ergs that one gram must be multiplied by the stupendous quantity $C^{2}\left(C\right.$ being $\left.3 \times 10^{10} \mathrm{~cm}\right)$, and the result is $9 \times 10^{20}$ ergs. Let us assume 
that such a transformation does take place in one second, remembering that to get the result into practical power units, namely, kilowatts, we must divide $9 \times 10^{20}$ by the number of ergs in a kilowatt, which is $10^{10}$. But the kilowatts that you then have created are $9 \times 10^{10}$, or 90 billion kilowatts. The transformation, then, of one single gram of matter per second should yield 90 billion kilowatts of power-almost too large an amount even for the imagination to grasp. In view of the immense number of grams of matter in the sun, it can be easily computed that the sun could keep pouring out heat at its present rate and last for hundreds of billions of years, and the assumption that such transformation can and does somehow take place would remove entirely the theretofore great mystery as to how the sun gets its heat. For, in view of Bethe's recent work at Cornell, practically all physicists now accept the evidence that the sun's heat is maintained by the transformation of mass into radiant energy; i.e., we regard this assumption as furnishing the correct explanation of the great mystery of the immensity of the heat output of the sun and the stars.

Here is, then, in fact, in the sun and stars the great inexhaustible source of atomic energy, though it is nothing but the actual source from which we have always known that we get all our power, namely, from present or past radiant energy shot down from the sun to earth and here bottled in oil or coal or wood or waterfalls. The total amount of available energy thus stored in coal and oil is unquestionably very many times larger than that which is stored in the unstable atoms of uranium and thorium, and which is also now practically releasable by man through the disintegration of uranium and thorium into lighter, more stable atoms. For reasons given in the next paragraph, this is called "packing-fraction energy."

For, according to the estimates of the astrophysicists, the universe is still 90 per cent hydrogen. Our sun is constituted largely thus. Bethe estimates that 80 per cent of the sun's atoms are hydrogen. At the enormous pressures and temperatures existing within the sun (temperature $=35,000,000^{\circ}$ ), four atoms of hydrogen can sometimes get together directly or indirectly and form one atom of helium, but the mass of a free hydrogen atom is 1.0082 atomic-mass units (AMU) and the mass of the four of them before their union was four times the foregoing number, or 4.033 units, while the directly measured mass of the helium atom formed by the combination of the four hydrogens is only 4.003 units, so that the difference, 0.03 AMU units, or roughly 1 per cent of the mass of the four hydrogen atoms involved, has been lost in the process of combining the four hydrogen atoms into one helium atom. The mass that has so disappeared is called the packing-fraction energy released in this particular reaction as radiant energy. The packing-fraction energy released in the building up of most of the common abundant atoms out of hydrogen, as they have in fact been built up, is not far per hydrogen atom from the above value involved in the building of helium.

When these packing-fraction energies were first worked out thirty-five years ago, some enthusiastic scientists followed their
Jules Verne urge and got into print with the statement that there was enough atomic energy in a cupful of sea water to drive the biggest ship across the Atlantic, since two out of three of the atoms in every molecule of $\mathrm{H}_{2} \mathrm{O}$ are hydrogen. They might have told a much bigger story than that, namely, that if it were possible to make the hydrogen in all the seas combine at once into helium, or indeed into any of the common elements, than we could probably explode the whole earth and transform it into a nebula with the packingfraction energy thus set free.

The difficulty is that so far as we can now see this particular packing-fraction job is one which the Great Architect assigned only to the titanic pressures and temperatures existing in the interiors of the stars, not to puny man or even to cold-blooded Mother Earth, for it takes a warmer lady than she is to do that job.

This situation has been so well known that for the past thirty-five years I have not heard of a scientist or even a newspaper columnist who grew jittery over the prospect of man's setting off that explosion. For the present, then, we have given up as unattainable on earth (save as the sun sends it down to us) this source of packing-fraction energy, incomparably greater than that obtainable from uranium, even if the reaction of its complete disintegration into smaller and stabler atoms, such as barium and krypton, for example, could be brought about on earth.

The only other kind of process which might release "packing-fraction energy" rapidly on earth and under man's control would be somehow to cause the heavy, unstable atoms of uranium and thorium to disintegrate into some of the common stable elements faster than they are doing through normal radioactive processes. This was the discovery made in 1939 of "uranium fission." It was found that when one of the uranium isotopes called U235 is sprayed with neutrons-which are essentially the nuclei of hydrogen atoms minus their positive charges - it instantly disintegrates into two nearly equal fragments with an emission of more neutrons which enter the surrounding U235 nuclei and split them up, thus starting a chain reaction which instantly spreads to all the U235 nuclei within reach. This constitutes an explosion some hundreds of thousands times more powerful, weight for weight, than TNT. This problem of thus instantly releasing the packing-fraction energy of uranium has been an elegant and very difficult scientific job, and it has been accomplished and spectacularly demonstrated to the whole world in the atomic bomb. The foregoing method of releasing atomic energy is limited, so far as we now know, to the two elements, uranium and thorium. These elements are already very rare and therefore very expensive, and of course if we should begin to use them up for ordinary power or heating purposes they would very quickly become rarer and their cost would skyrocket. Whereas, when the bottled sunlight energy, which we have in oil and coal, is all gone, say four thousand years hence, we can use water, wind, and tide power more fully than now, and grow fuel crops in the tropics, and also develop heat engines for using the sun's rays directly, as we do in a small way in solar heaters now, and thus get our power somewhat more expensively than now, it is true, but not prohibitively so.

The results of the fission of uranium can be applied in many useful ways, mostly biological, but in my judgment only where high costs are not an important factor. As an economical, long-range source of power for the power industry, this method is impractical because of the rarity of the uranium and thorium. I venture this opinion in spite of George Eliot's warning that prophecy is the most gratuitous form of mistake. Whose mistake it is, the next generation will know.

So far I have said nothing about the precise process by which packing-fraction energy is released. Please recall, then, that all atoms are built up out of the primordial atom of hydrogen-more accurately, out of protons and neutrons. Then, with the aid of Aston's packing-fraction curve (Fig. 1), we can see the whole story. In this curve, abscissas are simply the increasing atomic weight of the elements from 1 to 240 , and each ordinate is the accurately measured atomic mass of the element in question divided by the number of hydrogen atoms that have entered into its composition; i.e., it is the mass spectrograph's direct finding of the mass of the hydrogen atom after its incorporation into the structure of the atom under consideration. But, in becoming so closely packed together, these constituent hydrogen atoms have lost potential energy, and hence, according to Einstein's equation, have also lost mass. This is why the atom of hydrogen is heavier when it is free than when it is in any of its combinations.

With the aid of this packing-fraction curve, the release of atomic energy in any possible nuclear act of transmutation from a less stable atom to a more stable one can be seen at once.

Thus, the curve shows clearly the two sorts of atomic transformations which, if they can be made to take place, will release energy; namely, first the building up, or synthesis, of any of the elements out of the primordial element hydrogen.

But, secondly, the curve also shows that the mass of the hydrogen constituents of the very heavy elements at its extreme right end is greater than the mass of the hydrogen atoms that are constituents of the common elements lying along or near the bottom of the curve. Hence, any disintegration of these heaviest atoms, like uranium and thorium, into the stabler atoms that lie on the lower part of the curve must also be accompanied by a release of atomic energy, though of much lesser amount per hydrogen atom involved than in the case of the synthesis discussed above. It is thus synthesis, not disintegration, that is the great source of atomic energy.

The bottom of this curve is a position from which atoms cannot be transformed in to other atoms with any release of packingfraction energy at all. In other words, there is no atomic energy available on earth or, according to the generally accepted view of Bethe, even in the sun and stars, save packing-fraction energy, and packing-fraction energy never permits more than about 1 per cent of the mass energy of the participating hydrogen atoms to be transformed into heat. 


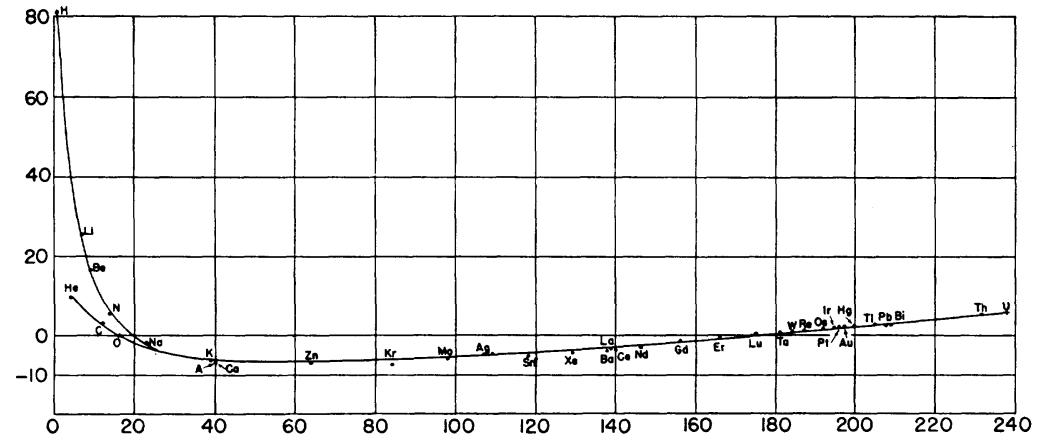

Fig. 1-The packing-fraction curve. Abscissas are the series of elements of atomic weight from 1 to 240 . Ordinates represent the difference between the weight of the uncombined hydrogen atom 1.0082 and the same atom in combination in each of the series of elements. This difference is the mass available for the transformation into radiant energy in accordance with the Einstein equation $E=m c^{2}$.

This puts a limitation on the present and future supply of energy from atomic sources that even some of the workers in nuclear physics may not yet have realized.

The following figures have a significant bearing on the available uranium packingfraction energy.

The total world supply of coal alone is estimated to be about $8,000,000,000,000$ tons. The present yearly consumption is about $2,000,000,000$. At this rate, the coal will last 4,000 years. The world's "easily available" supply of uranium has been estimated $^{1}$ at 30,000 tons having a fissionable content of 0.7 per cent, or 210 tons. The Smythe report gives, energy-wise, 1 ton of $\mathrm{U} 235=3,000,000$ tons of coal. The annual energy drain on coal beds would thus exhaust the world's supply of U235 in four months. If all uranium atoms were made fissionable (possible, but very costly), the foregoing uranium supply would last fortyfive years.

Again, how rare, from a practical point of view, uranium is can be seen from that portion of the history that I have myself followed closely since 1900, when I began searching the world over for uranium ores. For the first ten or twelve years after the discovery of radium in 1898 , it was the pitchblende ore from the Joachimsthal mines in Austria (now Czechoslovakia) that supplied the world demand for radium for scientific and therapeutic uses. Then, because of its extreme scarcity, the Austrian government put an embargo on the export of this ore. At this time Joseph Flannery, who had been president of the Vanadium Company of Pittsburgh and had promoted the use of vanadium as an alloy of steel, turned his attention to a careful study of the uranium situation. He found that "the ores of Europe were out of the question" because of the Austrian monopoly, and that "the few deposits that were found in other parts of the world were not of sufficient extent to justify serious consideration." However, in a desolate section of southwestern Colorado and northeastern Utah there were 800 square miles of carnotite deposits-sands on the grains of which the yellow oxide of uranium has crystallized out. These low-grade Colorado carnotites averaged less than 1 per cent uranium,

1 Clark Goodman, "Petroleum versus plutonium," Lamp, vol. 25, p. 10; February, 1946. while the Joachimsthal pitchblende had run up to 10 per cent uranium.

Knowing that both Professor Herbert McCoy and I had been working on uranium ores, Mr. Flannery approached us to find a young graduate student whom we had trained. We recommended to him Charles D. Viol, who went to Pittsburgh as director of Mr. Flannery's new Radium Laboratories of the Standard Chemical Company of Pittsburgh. Under Dr. Viol's directorship this company succeeded in developing a process for the extraction of radium from carnotite, turned out its first commercial radium (2.1 grams) in 1913, and between 1913 and 1918 produced 39 grams of radium element, which was then marketed at $\$ 125,000$ a gram. Dr. Viol also estimated that the total radium production in the United States up to 1919 was 55 grams of radium element, "probably more than half of all the radium produced in the world up to that date." By 1921 this company had raised its total production from the Colorado carnotites to 72 grams. In the single year of 1920 it produced 18.5 grams. Further, in view of the fact that the United States Bureau of Mines had estimated the total radium content of the Colorado carnotites to be but 135 grams all told, and that the Standard Chemical Company's carnotite holdings were much larger than those of any other single company, the latter organization made a careful survey (in part by systematic diamond drilling), and estimated the total Colorado carnotite's content of radium metal as at least 500 grams, in place of the Bureau of Mines' estimate of 135 grams-excellent agreement as to order of magnitude.

In 1922 I was C. R. B. Exchange Professor to Belgium and was a guest of $\mathrm{Mr}$. Franqui, Belgian industrialist and financier, who, as a young man, had been instrumental in acquiring for his country the Belgian Congo. He told me he was in a position to destroy the United States' monopoly in the production of radium, for, said he, "Your poor carnotite ore - and there is no other available to you-cannot compete with the new rich Congo pitchblende ore, which occasionally runs up to 15 per cent uranium metal."

Mr. Franqui made good on his boast, and within two years the two chief radiumproducing companies in the United States had gone out of business, while the Belgian Congo took over the world's monopoly in the production of uranium, holding it for some ten years, until competition from the Big Bear Lake uranium mines in Canada began to bring down the price somewhat. My memory is that the second gram of radium presented to Madame Curie cost but $\$ 70,000$. But even in $1940-1945,90$ per cent of all the 1,100 tons of pitchblende ore which was purchased by the United States and used in the development of the uranium bomb came from the Belgian Congo.

Thus, after fifty years of search by government bureaus of mines and private individuals and companies, there are now but two places in the world-Canada and the Belgian Congo-from which uranium ores can be obtained in considerable commercial quantities, and two more places-Colorado and Joachimsthal-where smaller deposits exist. In view of that record and the abovequoted abundance figures, I do not anticipate that either intelligent governments or intelligent individuals will use uranium for any major fuel or power purposes. It is too valuable a material for scientific purposes, for public health purposes, and for such industrial purposes as require small quantities (luminous paints, alloys, etc.) to be wasted on major power projects so fully provided for by the inexhaustible supplies of solar energy, past or present. According to the Atomic Energy Commission, uranium and thorium are the only elements which have a chance in disintegrating of releasing atomic packing-fraction energy, and there is no available energy save packing-fraction energy. Because of the extreme rarity of these elements, wisdom calls for their conservation rather than for their use for fuel or power.

Alfred Nobel, a great pacifist, was convinced that his invention of nitroglycerine had done more to bring about the elimination of war than all the sermons and peace conferences had ever done or could ever do; and with the experiences of the two world wars of the past thirty years before them, the great majority of intelligent men had determined, even before the advent of the atomic bomb, to join the ranks of those determined to put a stop, if possible, to international wars, since otherwise the race is headed for self-annihilation. The great service to mankind of the advent of the atomic bomb has been to make as clear as crystal, to all classes and conditions of men the world over, the necessity for such action. In my judgment, no other service that the study of atomic energy can render to mankind is likely to be in any way comparable to this service; and the other services could all be profitably dis. carded if this one succeeds.

The necessity that it has placed upon all mankind to find a substitute for war in the handling of its international relations is that which, in itself, without reference to further inventions of any kind, will make $a$ new world; and its influence in making a new world will probably be greater than all other influences combined. Without it, there certainly will be no worth-while new world. I expect the influence of industrial applications to be wholly negligible in comparison with this supreme service. 